Special issue of the International Conference on Computational and Experimental Science and Engineering (ICCESEN 2014)

\title{
Investigation of External Radiation Dose Changes in Some X-ray Applications
}

\author{
A. CoşKun and B. Mavi \\ Amasya University, Science and Art Faculty, Physics Department, Amasya
}

\begin{abstract}
Ionizing radiation is commonly used in diagnostic and therapeutic applications in medicine. Therefore, both staff and patients are exposed to the biological influence of radiation. Biological effects and damages are proportional to the irradiation.In this study the radiation dose to human in the patient room and the technician room at computed tomography and X-ray units were measured and compared for different situations.
\end{abstract}

DOI: 10.12693/APhysPolA.128.B-365

PACS: 87.57.Q-, 87.55.N-, 87.53.-j

\section{Introduction}

Since the creation of universe all creatures experience the effects of radiation to their structure, mainly due to natural radionuclides.In addition to this the developement of technology bring another aspect of artificial radiation, e.g., X-rays and radioactive substances of nuclear practices. It is very hard to estimate the biological results of exposure to radiation doses due to variety of factors, physical and personal. The same dosage rate can invoke different responses, depending on individuals or configuration of the system [1].

Natural radiation is responsable for $85 \%$ of total dose. Remaining $15 \%$ in $99 \%$ come from medical substances and diagnostic or therapeutical radiological appliances. Computed tomography examinations share is only $5 \%$. Because of augmented radiation level X-rays are not appropriate for some cases [2]. Table shows effects of some $\mathrm{X}$-ray examination over active dosage exposure rates.

TABLE

X-ray examination share in active dosage exposure rates [3].

\begin{tabular}{c|c|c}
\hline \hline \multicolumn{2}{c|}{} & Dose [mSv] \\
\hline \multirow{4}{*}{ X-ray } & breast & 0.14 \\
& arms, legs & 0.06 \\
& knuckle & 0.83 \\
& head & 0.07 \\
& abdomen & 0.53 \\
\hline \multirow{2}{*}{ mammography } & scanning & 0.07 \\
& clinic & 0.21 \\
\hline \multirow{2}{*}{ computed tomography } & head & 2.3 \\
& body & 13.3
\end{tabular}

In 2000, according to the Radiation Safety Regulation in the Official Gazette in Turkey; "Consecutive five-year average effective dose for radiation workers is $20 \mathrm{mSv}$, if not exceed $50 \mathrm{mSv}$ in any one year. Effective dose per year for people not exposed to radiation professionally should not exceed $1 \mathrm{mSv}$.In special cases; consecutive five-year average of $1 \mathrm{mSv}$ is allowed up to $5 \mathrm{mSv}$ per year [4].

\section{Material and method}

In this study some tests of radiation doses were designed. Fluke Victorian ASM990 radiation detectors was used [5]. Regulations concerning X-rays or $\gamma$-rays specialists who are professionally exposed to radiation admits them special holiday rights. Workers are entitled to 4 week health leave each year, besides regular 3 week annual leave. Four weeks of leave must be compulsorilly continuous. This data are essential for calculations of yearly workers radiation load.

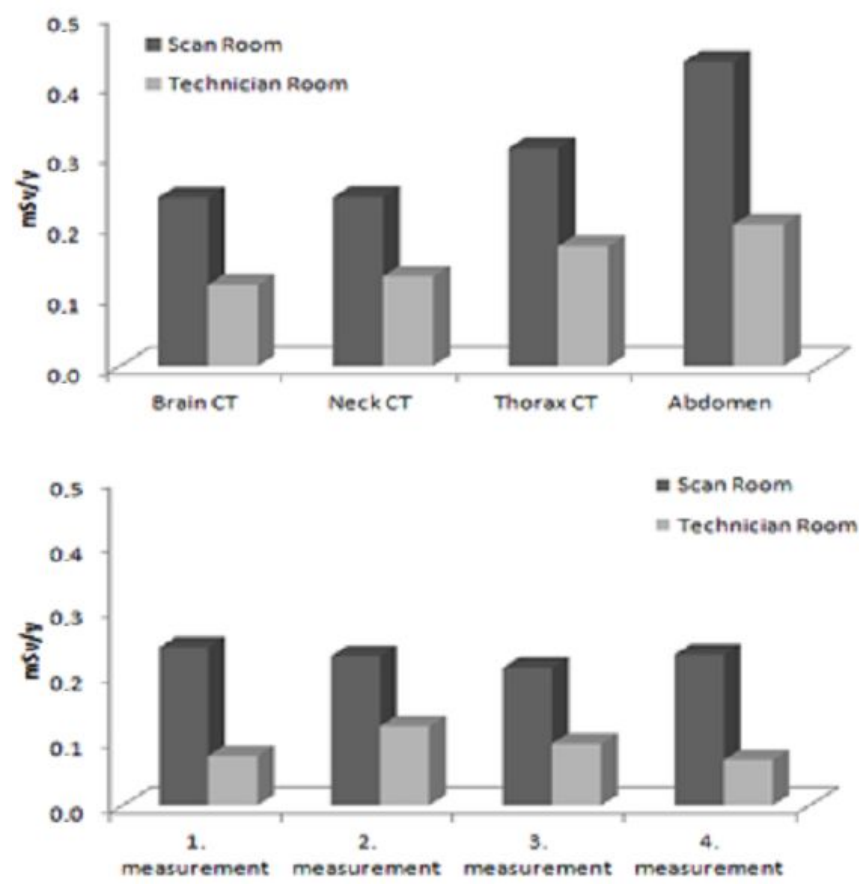

Fig. 1. CT unit radiation dose and values in the technician's room and scan room.

The study was done at Amasya University Training and Research Hospital in the Serefeddin Sabuncuoğlu $\mathrm{X}$-ray and CT unit. Results present the level of radiation registrated during the irradiation phase. Shooting room measurements were taken inside of compartment 
with a detector tube. Technician room measurements were taken in the computer proximity, where the technician stays during the shooting. Recalculated results are shown in Fig. 1 (top). In Fig. 1 (bottom) results for different operational modes of the apparatus:

1. still radiograms direct system $(90 \mathrm{kV}, 20 \mathrm{mAs})$;

2. CT examination $(88 \mathrm{kV}, 20 \mathrm{mAs})$,

3. chest X-ray $(80 \mathrm{kV}, 8 \mathrm{mAs})$,

4. sinus radiography $(85 \mathrm{kV}, 25 \mathrm{mAs})$

are presented. Changes in the background radiation field are shown in Fig. 2. Time dependency of dose vs. time of exposure for apparatus working in mode $85 \mathrm{kV}$, $20 \mathrm{mAs}$ during the application and after 120, 240, 300 and $360 \mathrm{~s}$ is presented in Fig. 3.

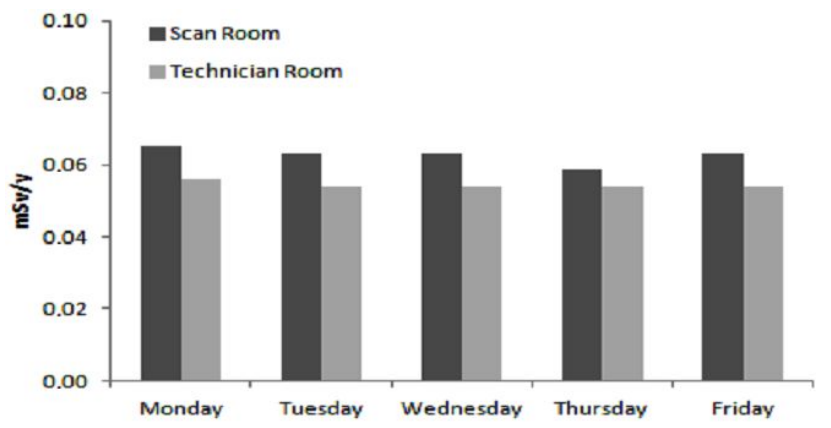

Fig. 2. Background-dose X-ray unit tracking.

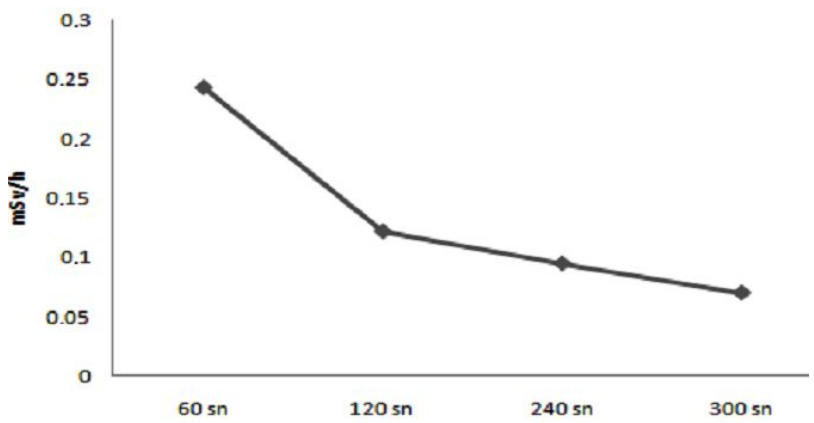

Fig. 3. Dose-time relationship X-ray room.

\section{Discussion and results}

There are three basic principles of radiation protection. These are: lessen exposure to the radiation source (time), avoiding the radiation source (distance) and put obstacles in between the radiation source and workers to weaken the intensity of radiation (shielding).

Radiation workers can not stay away completely so exposure time and distance from the radiation source are decisive factors for protecting the employees. Results of this study emphasises its importance once again.

There are noteworthy differences among the doses in the examination room and the measurement technicians room, presented in Fig. 1. This shows that shielding significantly reduces the level of radiation and create a safer environment for employees.

The measurement results given in Fig. 1 reveal the differences in the radiation emitted to the environment depending on type of examination. The comparison of the results with the requirements of the Radiation Safety Regulation shows, that the annual allowable radiation limit of $50 \mathrm{mSv}$ is fulfilled. The observed results are significantly below the exigences.

\section{Acknowledgments}

This study includes the results from M.Sc. Thesis prepared at Amasya University of Science and Technology, Department of Institute of Nuclear Physics.

The authors are grateful to unit managers and staff of the Şerefeddin Sabuncuoğlu Amasya University Training and Research Hospital, Röntgen-computed tomography, for help.

\section{References}

[1] İ.İ. Güçlü, Ph.D. Thesis, İstanbul Üniversitesi, Fen Bilimleri Enstitüsü, 2006.

[2] How much dose received from Röntgen Film?, TAEK publications, 2009, (in Turkish).

[3] Sources and Effects of Ionizing Radiation, UNSCEAR Report 2000.

[4] Radiation Security Document 2000, Resmi Gazete, 2000, (in Turkish).

[5] ASM-990 Series Advanced Survey Meter, Fluke Biomedical 2007. 